\title{
Advanced Asia's health systems in comparison
}

\author{
Robin Gauld $^{\mathrm{a}, *}$, Naoki Ikegami ${ }^{\mathrm{b}}$, Michael D. Barr ${ }^{\mathrm{c}}$, \\ Tung-Liang Chiang ${ }^{\mathrm{d}}$, Derek Gould ${ }^{\mathrm{e}}$, Soonman Kwon ${ }^{\mathrm{f}}$ \\ a Department of Preventive and Social Medicine, University of Otago, PO Box 913, Dunedin, New Zealand \\ ${ }^{\mathrm{b}}$ Department of Health Policy and Management, Keio School of Medicine, Tokyo, Japan \\ ${ }^{\mathrm{c}}$ School of History, Philosophy, Religion and Classics, University of Queensland, Brisbane, Australia \\ ${ }^{\mathrm{d}}$ College of Public Health, National Taiwan University, Taipei, Taiwan \\ e Kwok and Gould Consulting Limited, Hong Kong \\ ${ }^{\mathrm{f}}$ School of Public Health, Seoul National University, Seoul, South Korea
}

\begin{abstract}
There is growing interest in comparing patterns of social and health service development in advanced Asian economies. Most publications concentrate broadly on a range of core social services such as education, housing, social security and health care. In terms of those solely focused on health, most discuss arrangements in specific countries and territories. Some take a comparative approach, but are focused on presentation and discussion of expenditure, resourcing and service utilization data. This article extends the comparative analysis of advanced Asian health systems, considering the cases of Japan, South Korea, Taiwan, Hong Kong and Singapore. The article provides basic background information, and delves into common concerns among the world's health systems today including primary care organization, rationing and cost containment, service quality, and system integration. Conclusions include that problems exist in 'classifying' the five diverse systems; that the systems face common pressures; and that there are considerable opportunities to enhance primary care, service quality and system integration.
\end{abstract}

(C) 2006 Elsevier Ireland Ltd. All rights reserved.

Keywords: Health systems; Comparative policy; Japan; South Korea; Taiwan; Hong Kong; Singapore

\section{Introduction}

In recent years there has been growing interest in comparing patterns of social and health service development in advanced Asian economies, resulting in several articles and books [1-6]. Much of this material concentrates more broadly on a range of core social

\footnotetext{
* Corresponding author. Tel.: +64 34798632 ; fax: +64 34797298.

E-mail address: robin.gauld@otago.ac.nz (R. Gauld).
}

services such as education, housing, social security and health care. There has also been interest in, and analysis of, whether there are specifically 'Asian' welfare models that differ from those in the Western world. In terms of publications solely focused on health care, most discuss arrangements in specific countries and territories. Some, such as Holliday [7], Ramesh [8] and Ramesh and Holliday [9], have a comparative approach, but are focused largely on presentation and discussion of expenditure, resourcing and service utilization data. 
This article extends the comparative analysis of advanced Asian health systems, considering the cases of Japan, South Korea, Taiwan, Hong Kong and Singapore. The article provides basic background information, but also delves into common concerns among the world's health systems today including primary care organization, rationing and cost containment, service quality, and system integration. First, the article provides background information and health indicators for the five jurisdictions. Second, it describes each of the five systems in terms of regulation, funding and provision. Third, it draws comparisons between them. The conclusion sets out key themes, including that problems exist in 'classifying' the five diverse systems; that the systems face common pressures; and that there are considerable opportunities to enhance primary care, service quality and system integration.

\section{Background information}

The five jurisdictions featured in this article are all developed market-based economies. South Korea, Taiwan, Hong Kong and Singapore have all, at one time or another, been colonies and collectively deemed 'tiger economies' [5]. Despite recent mediocre economic performance, Japan remains one of the world's wealthiest states. Singapore might be described as a majoritarian democracy that facilitates semi-authoritarian government. Taiwan and Korea have both been pluralist democracies only since the late 1980s. Korea was previously under military control; Taiwan was ruled by the Kuomintang. Japan has a longer history as a pluralist democracy. Hong Kong has an executive-led government dominated by appointed Ministers and civil servants.

Table 1 presents data from each of the five territories. All have low fertility rates, with Hong Kong the world's lowest. All have increasing median ages and proportions of the population moving into the 'over 65 years' bracket. This is of concern to policymakers for, as noted by the OECD of its 30 member countries, '... population ageing will cause total health care spending to increase by an average of nearly $2 \%$ of GDP by 2050' $[10,19]$. Japan, Hong Kong and Singapore have some of the world's lowest infant mortality rates and longest life expectancies.

With the exception of Japan, all have low levels of health care expenditure as a percentage of GDP (the OECD average is around $8.5 \%$ ). Expenditure growth is a common concern, as noted above. For example, from 1990 to 2001, Japan's health spending grew at around $3.8 \%$ per annum against overall GDP growth of $2.3 \%$. Similarly, South Korea's health spending grew at $7.5 \%$, compared with a GDP expansion rate of around 5.2\% [11].

Interesting divergences are evident in the public portion of total health expenditure, with Singapore very much at the lower end of the spectrum. South Korea and Hong Kong have low levels of public expenditure

Table 1

Key indicators in comparison, 2002

\begin{tabular}{llllll}
\hline & Japan & South Korea & Taiwan $^{\text {a }}$ & Hong Kong & Singapore $^{\mathrm{a}}$ \\
\hline Population (million) & 127.2 & 48.1 & 22.5 & 7.8 & 4.6 \\
\% population $>$ 65 yrs & 18.6 & 7.9 & 9.0 & 11.0 & 7.2 \\
Median age & 42 & 33.2 & 33.2 & 37.5 & 34.5 \\
Area $\left(\mathrm{km}^{2}\right.$ ) & 377835 & 98480 & 35980 & 1092 & 693 \\
GDP/capita (US\$ PPP) & 28700 & 19600 & 18000 & 27200 & 25200 \\
Live births per woman & 1.38 & 1.17 & 1.34 & 0.96 & 1.24 \\
Infant mortality rate per 1000 live births & 3.3 & 7.31 & 6.8 & 2.3 & 3.57 \\
Life expectancy (m/f) & $77.63 / 84.41$ & $72.84 / 80.01$ & $73 / 78.8$ & $78.6 / 84.3$ & $76.8 / 80.6$ \\
GDP health expenditure (\%) & 8.0 & 5.9 & 6.1 & 5.1 & 3.6 \\
Total health expenditure per capita (US\$ at PPP) & 2131 & 948 & 776 & n/a & 993 \\
Public spending \% & 77.9 & 54.4 & 65 & 51.9 & 25 \\
Practising physicians per thousand population & 1.9 & 1.4 & 1.4 & 1.4 & 6.5 \\
Obesity prevalence \% population (BMI > 30) & 3 & 3 & 4 & 6 \\
Daily smokers \% population (m/f) & $47.4 / 11.5$ & $64.8 / 5.5$ & $45.0 / 4.1$ & $25.2 / 4.4$ & $24.2 / 3.5$ \\
\hline
\end{tabular}

Sources: [11,13-18].

a 2003. 
(compared with the OECD average of around $75 \%$ ) yet, as discussed below, their mix of policies, funding and service delivery arrangements is such that there is virtually universal health service access. The public share is higher in Japan and Taiwan.

South Korea, Taiwan, Hong Kong and Singapore have lower concentrations of practising physicians, as compared to an OECD average of 2.9 per thousand population [12]. However, the picture is a complex one as there is a strong presence in all five jurisdictions of traditional medicine practitioners and utilization. In Hong Kong, for instance, the number of Chinese medicine practitioners is equal to that of Western medicine. It remains unclear, however, what impact the presence of traditional medicine has on the utilization and number of practitioners of modern medicine.
A wide range of environmental and lifestyle factors influence population health. Tobacco consumption is a key concern for health policymakers around the globe as a cause of disease and death. It is a particular concern in the Asian region where the smoking prevalence is high. As Table 1 indicates, smoking rates are particularly high among males in Japan and South Korea, while the overall figures are offset by lower female rates. Obesity, and its potential to lead to illnesses such as diabetes and heart disease, is emerging as a major issue for policymakers in the West and, more recently, Asia. While the obesity rate among the five territories is low, compared with rates of well over $20 \%$ in many Western countries, there is growing recognition in Asian societies that obesity, particularly among the young, is an increasing problem (The Economist, 9 May 2003).

Table 2

Regulation, funding and provision in comparison

\begin{tabular}{|c|c|c|c|c|c|}
\hline & Japan & South Korea & Taiwan & Hong Kong & Singapore \\
\hline Regulation & $\begin{array}{l}\text { Ministry of Health, } \\
\text { Labor and Welfare }\end{array}$ & Ministry of Health & $\begin{array}{l}\text { Department of Health } \\
\text { and subordinates }\end{array}$ & $\begin{array}{l}\text { Health, Welfare and } \\
\text { Food Bureau; others } \\
\text { such as Traditional } \\
\text { Chinese Medicine } \\
\text { Council }\end{array}$ & Ministry of Health \\
\hline Funding & $\begin{array}{l}\text { Social insurance } \\
\text { with co-payments; } \\
\text { three tiers of social } \\
\text { insurance with } \\
\text { multiple providers; } \\
\text { common payment } \\
\text { schedule }\end{array}$ & $\begin{array}{l}\text { Social insurance with } \\
\text { high patient } \\
\text { co-payments; single } \\
\text { social insurer; Medicaid } \\
\text { scheme and private } \\
\text { insurance }\end{array}$ & $\begin{array}{l}\text { Social insurance with } \\
\text { co-payments; single } \\
\text { social insurer; direct } \\
\text { government financing }\end{array}$ & $\begin{array}{l}\text { Tax-based } \\
\text { government funding; } \\
\text { limited co-payments } \\
\text { for public services; } \\
\text { private service } \\
\text { payments and } \\
\text { insurance }\end{array}$ & $\begin{array}{l}\text { Medical savings } \\
\text { accounts with } \\
\text { co-payments; four } \\
\text { separate schemes }\end{array}$ \\
\hline Provision & $\begin{array}{l}\text { Mix of public and } \\
\text { private; emphasis on } \\
\text { outpatient services }\end{array}$ & $\begin{array}{l}\text { Private dominance of all } \\
\text { service delivery, except } \\
\text { public health; } \\
\text { considerable provider } \\
\text { competition }\end{array}$ & $\begin{array}{l}\text { Private dominance of } \\
\text { all service delivery, } \\
\text { except public health; } \\
\text { considerable provider } \\
\text { competition }\end{array}$ & $\begin{array}{l}\text { Primary care private } \\
\text { dominated; extensive } \\
\text { traditional Chinese } \\
\text { medicine. Hospital } \\
\text { care public dominated }\end{array}$ & $\begin{array}{l}\text { Primary care } \\
\text { private dominated; } \\
\text { hospital care } \\
\text { public dominated; } \\
\text { two regional } \\
\text { service delivery } \\
\text { clusters }\end{array}$ \\
\hline Comments & $\begin{array}{l}\text { System lacks } \\
\text { integration or } \\
\text { primary care } \\
\text { emphasis; limited } \\
\text { quality initiatives; } \\
\text { no formal rationing } \\
\text { but costs controlled } \\
\text { by service fee } \\
\text { negotiation process; } \\
\text { aged-care inpatient } \\
\text { services heavily } \\
\text { subscribed }\end{array}$ & $\begin{array}{l}\text { Sustainability of social } \\
\text { insurance scheme } \\
\text { questionable; high } \\
\text { patient co-payments } \\
\text { pose barriers; system } \\
\text { lacks integration or } \\
\text { primary care emphasis; } \\
\text { limited quality } \\
\text { initiatives; no formal } \\
\text { rationing }\end{array}$ & $\begin{array}{l}\text { Sustainability of } \\
\text { social insurance } \\
\text { scheme questionable; } \\
\text { system lacks } \\
\text { integration or primary } \\
\text { care emphasis; limited } \\
\text { quality initiatives; no } \\
\text { formal rationing }\end{array}$ & $\begin{array}{l}\text { Extensive state } \\
\text { involvement in } \\
\text { hospital services, but } \\
\text { minimal involvement } \\
\text { elsewhere; system } \\
\text { lacks integration or } \\
\text { primary care } \\
\text { emphasis; limited } \\
\text { quality initiatives; } \\
\text { restricted public } \\
\text { health capacity; no } \\
\text { formal rationing }\end{array}$ & $\begin{array}{l}\text { Notable state } \\
\text { control of all } \\
\text { system } \\
\text { components to } \\
\text { keep costs down; } \\
\text { some integration; } \\
\text { strong public } \\
\text { health focus }\end{array}$ \\
\hline
\end{tabular}




\section{The five health systems: regulation, funding, provision}

The five health systems discussed in this article differ from one another in multiple ways, potentially thwarting comparison. Despite this complexity, there is general agreement in the literature that health systems (and related policy) can be studied in terms of how they are regulated (or governed) and funded, and how services are provided (see for example [19]). This framework guides the system descriptions that follow and is used to present summary information in Table 2.

\subsection{Japan}

Japan's health system is presided over by the central Ministry of Health, Labor and Welfare which has several responsibilities. These include policy development and advice, data collection, and health status and sector monitoring. In addition, the ministry regulates Japan's social insurance funding system including negotiating and controlling the schedule of service fees, as well as administering some insurance funds. More recently, the ministry has been involved, along with the Japan Medical Association, in sponsoring of quality and cost control mechanisms, such as creation of a hospital accreditation agency and the Diagnosis and Procedure Combination, a payment system introduced to several hundred hospitals.

Social insurance dominates Japan's health funding. The system is complex and deeply rooted in history. There are three separate tiers of social insurance schemes (with many variations within). The first tier features plans for public sector and large company employees, and those managed by the Mutual Aid Association. The second is a single governmentmanaged plan for those in small to medium enterprises. The third tier consists of plans established by municipalities, the so-called 'citizens' health insurance', for the self-employed and pensioners. The second and third tiers receive substantial government subsidies for those on low incomes. All plans are governed by a schedule of common entitlements and fees meaning virtually universal and equitable access to services. Premiums differ between the tiers and are based on income. The schedule of fees paid on provider claims is the key means for cost con- tainment. The fees paid for most surgery and new high-tech procedures are set low, so that providing these services tends to result in a net loss. However, physicians provide such services as they find them professionally rewarding and salaries are not linked to hospital profits. Thus, most surgery is provided in public hospitals where costs are governmentsubsidized. When the fee schedule is revised, fees are reduced for services and drugs that show large volume increases; similarly, those that are underutilized, yet deemed important, receive fee increases. The fee setting process is one of negotiation, with the health ministry making final decisions after hearing the views, via a 20-member council, of payers, providers and the public, as well as taking into consideration the government's wider financial situation.

Virtually all Japanese clinic-based physicians are sole practitioners, professing some specialty, but essentially providing primary care. About a third of practices have up to 19 beds for inpatient care. The majority of hospitals are owned and run by individual physicians, and most began as expansions of clinics. The remaining hospitals are public sector or owned by non-government organizations. As these hospitals receive capital subsidies they tend to provide most advanced care. They also feature large outpatient departments and most patients come without referral as there is no gatekeeping in the system. This unrestricted access to even tertiary hospitals means there are no waiting lists for treatment. Provision is weighted toward outpatient treatment, so Japan has one of the highest rates of physician visits and lowest of hospital admissions among advanced countries [11]. Many of Japan's smaller hospitals serve as de facto aged-care facilities. As a result, nearly half of all inpatients are 65 or older, and a third have been hospitalized for more than a year. A notable feature of Japan's public health landscape is an elaborate and popular screening programme, some directly provided by public health centres. These have been driven by a policy of allowing the insurers that insure those with good risk to offer elaborate screening programmes, but also by history, with screening seen to be the primary mechanism for eradicating tuberculosis. Unlike Hong Kong, South Korea and Taiwan, there are no separate schools of Chinese medicine in Japan. 


\subsection{South Korea}

Health care has become a centrepoint of government policy in South Korea since the 1970s when the Health Insurance Law established a national health insurance system with coverage extended to the entire population by 1989 . The rapid extension of social health insurance and achievement of universal population coverage is attributable to rapid economic development as well as an authoritarian regime seeking political legitimacy. In 2000, multiple social insurers were merged into a single National Health Insurance Corporation. The government today has a key role in health insurance policy, regulating and managing mandatory employmentbased payments to the insurer, in setting fee levels to be paid to health care providers, setting benefit coverage, and regulating and supervising the National Health Insurance Corporation.

Although characterised as a system funded by social health insurance with universal coverage, there is considerable cost sharing by way of patient charges. However, in 2000, the government placed a high priority on extending benefit coverage, and about $55 \%$ of total health expenditure is from public financing (tax and social insurance). Social insurance presently pays for $44 \%$ of outpatient and hospital care. The government, via public health services and a Medicaid scheme (designed for those unable to afford insurance premiums), contributes a further $11 \%$. Around $45 \%$ of health funding in South Korea is from private sources. About $37 \%$ of health expenditure is from patient payments, and private insurance and other sources provide the remainder $(8 \%)$. Regulated fees-for-service are paid by the national insurer to provider claimants. This system has provided incentives for providers to increase the volume and intensity of services provided and to offer services with greater margins. It has also affected the market for medical professionals, with specialties that are funded more generously, such as psychiatry, dermatology and ophthalmology, attracting more trainee applicants. In the late 1990s, a Diagnosis Related Group (DRG) payment system was introduced on a pilot basis. This has produced positive results, and some cost containment. More intensive reform of the payment system is required for the longer-term fiscal sustainability of the social health insurance system.

The South Korean health system relies heavily on for-profit hospitals that, in most cases, physicians own and manage. Less than $10 \%$ of hospitals are public. Medical services provided by public hospitals are not free, but they usually provide cheaper (uninsured) services and have a larger share of Medicaid patients. Many physician clinics have small inpatient facilities, and hospitals also have large outpatient clinics, leading to competition among hospitals and physician clinics in some clinical areas. Primary medical care is not well developed, and most practising (officebased) physicians are board-certified specialists. In 2000, a law change, heavily opposed by the medical profession, saw dispensing separated from medical practice, so that dispensing is now carried out by pharmacists [20]. Patients are free to seek services from any provider. The fee-for-service system discourages referrals between providers, as this means loss of income, and there is considerable provider competition. Traditional medicine is popular, but only some services are covered by social insurance. Health in South Korea tends to be viewed as the responsibility of individuals not the state, so health promotion and public health policy is not extensive. In 2004, there was a large increase in tobacco tax, which is being channelled into health promotion. The government is now expected to play a more active role in health promotion.

\subsection{Taiwan}

Taiwan's health system history has similarities to South Korea's, in that Taiwan also has a public funding system based on the Japanese social insurance model. However, the present national health insurance structure was not put in place until the mid-1990s, under considerable political pressure to do so and in recognition that universal health care access was central to a stable democratic state. Taiwan's health system governance involves oversight of a mix of public and private institutions. The public administration features a National Department of Health and nine subordinate agencies, including a Centre for Disease Control, Bureau of Health Promotion, Bureau of National Health Insurance, and Committee on Chinese Medicine and Pharmacy. Via its subordinate agencies, the health department is, thus, responsible for regulating national health insurance, public hospitals and public health services, as well as the predominant private sector providers. 
Again, funding in Taiwan is mixed, although favouring the public purse. The National Health Insurance Scheme is the major source of health financing, covering $97 \%$ of the population. This provides comprehensive benefits, including acute care, pharmaceuticals, dental care and Chinese medicine, financed mainly by payroll tax. In 2002, social insurance accounted for $57 \%$ of total health expenditure, while direct patient co-payments and government financing account for 31 and $8 \%$, respectively. Like South Korea, the insurer pays providers on a fee-for-service basis, on a fixedfee schedule, with patients free to choose between providers. An economic downturn in recent years, combined with increasing health care costs and universal access to unlimited services, has led the National Health Insurance Bureau to apply premium increases. The source of considerable political and public discontent, these have not been sufficient to meet rising costs leading to calls for insurance system redesign. Taiwan has also experimented with an outcomes payment scheme aimed at quality improvement.

The provision landscape in Taiwan is complex. Ninety percent of hospitals are private, supplying $65 \%$ of hospital beds. While fewer in number, public hospitals tend to be larger. Forty percent of public hospitals are central government owned, $22 \%$ by local government, and $38 \%$ by military and veterans administration. In practice, all Taiwanese hospitals behave like private businesses and keenly compete for patients regardless of ownership or size. This means there is little cooperation among providers or health system integration. Patients tend to patronize larger hospitals, with social insurance claims for inpatient and outpatient services increasing 48 and 25\%, respectively, between 1996 and 2000 [21]. In contrast, claims at smaller hospitals increased by $11 \%$, while district hospital claims declined by 5\%. Analysis shows that, through this period, the expansion of large hospitals was responsible for $30 \%$ of health spending growth [22]. In addition to hospitals are general practice and Chinese medicine clinics; the latter provide around $10 \%$ of primary care consultations. Most general practice clinics are sole practices; less than $20 \%$ are partnerships or group practices. Since 1997, there has been separation between prescribing and dispensing. Consequently, many practices employ pharmacists. Quality measures in Taiwan require attention [23]. These largely entail structural approaches including a comprehensive hospital accred- itation programme. However, short patient consultations, over-prescribing and incentives primarily based on increasing revenue are the cause of systemic quality problems. Public health, as noted, is a Department of Health responsibility, with services provided through local agencies. Like South Korea, private domination in health provision means public health is not accorded high priority.

\subsection{Hong Kong}

Hong Kong's health sector is governed by a complex set of institutions. At the central government level, an appointed health minister presides over the Health, Welfare and Food Bureau, the chief responsibility of which is to produce policy advice and implement government policy, monitor the sector, and fund health services. The Bureau funds and oversees the work of the Hospital Authority (which manages Hong Kong's 41 public hospitals and associated specialist and general outpatient clinics), the Department of Health and Centre for Health Protection (responsible for disease control and other public health functions), and the Food and Environmental Hygiene Department. The government and Bureau also have a role in providing a regulatory framework for the private sector, including doctors, hospitals and traditional Chinese medicine practitioners following creation, in 1999, of the Traditional Chinese Medicine Council. However, beyond this, the private sector is largely self-regulatory, with government refraining from intervention. This is partly a function of health care funding, as discussed in the next paragraph.

As noted, around half of Hong Kong's health expenditure comes via government, funded from general taxes. The remaining funding is from private payments and insurance. Government funding presently goes only to services provided in public facilities. The Hong Kong government is the predominant funder of hospital care, with public hospitals, managed on the government's behalf by the statutory Hospital Authority. This provides $94 \%$ of all hospital services, accounting for $90 \%$ of all government health expenditure. Inpatient charges of HK\$ 100 (US\$ 16) per night are a fraction of the total cost of service provision and often waived due to a policy of service in accordance with need not ability to pay. Public expenditure has been progressively increasing, with government considering 
introduction of Singapore-style medical savings accounts [24]. In contrast, primary care medicine is largely private, receiving no government funding, although a government advisory committee recently proposed that government should buy services from private doctors in order to relieve pressure on the public sector [25]. Private hospitals are also separate from the state. Private insurance finances around $30 \%$ of outpatient visits. Many insurers provide workplace plans, enrolling subscribers with contracted practitioners.

The government's traditional non-interventionist public policy approach has propagated a highly compartmentalized health system [26]. The public and private sectors operate independently of one another, meaning there is no integration between primary and secondary care. Many patients simultaneously patronise practitioners of traditional and Western medicine for treatment of the same illness. Since establishment of the Hospital Authority in 1990 public hospital quality has improved and patronage increased, placing pressure on the public budget and the 12 private hospitals whose market share has decreased. Organization of primary care medicine is limited, with most practitioners in sole business and responsible for both prescribing and dispensing their own medicines. The Hospital Authority, as noted, runs outpatient clinics, but quality is poor with long queues. Private doctors provide around $55 \%$ of primary care consultations, public clinics around $20 \%$ and traditional Chinese medicine practitioners $23 \%$. Compartmentalization posed problems during the 2003 SARS outbreak, when no single part of the health system seemed responsible for coordination and there were difficulties with cross-sector communications and collaboration [27]. Also problematic was the fact that the Department of Health had no legal powers of intervention. Since then, the government has worked to fuse the parts of the health system, mainly by creating the data collection and disease monitoring agency, the Centre for Health Protection. However, there remains considerable concern about the need for more fundamental system reform.

\subsection{Singapore}

The Singapore government is heavily involved in health system regulation and plays a key role in terms of 'balancing' the system with a mix of policies that control expenditure and service costs. The government has core functions with regard to governance and administration of Singapore's health insurance system, and the network of public providers. A Ministry of Health presides over the system, regulating, administering and monitoring insurance funds and performance, and that of government-funded hospitals. It also has public health and some primary care responsibilities.

Singapore's insurance system differs from the three schemes outlined above in that there is little risk pooling. Instead, insurance is focused on individuals in the spirit of personal responsibility, with the schemes set up as savings accounts. There are four quite separate government-run schemes. First, is Medisave, to which those in the paid workforce must contribute, building savings to fund patient co-payments (at least 19\% of cost) in the event of hospitalization. Medisave accounts earn interest and form part of one's estate upon death. To protect accounts from being run down, there is a strict fees schedule and Medisave will not pay above this. Similarly, various high-cost services, routinely funded in other developed countries, are not covered. Next, is MediShield, a voluntary additional scheme that pays expenses for major or prolonged illness but with various services excluded. Third, is Medifund, an endowment fund that provides charity-style relief to those unable to meet any costs. Interest from the fund is distributed to public hospitals and charities that consider patient applications for assistance. Finally, is ElderShield, a new scheme designed to contribute towards the costs of nursing and home care for the aged. Nearly one-third of the population is currently covered by generous employer schemes negotiated before the current systems were put in place, but the size of this group is being gradually reduced by death and active government intervention.

Government is also involved in micro-managing provision. It ensures that public hospital charges are kept down, in turn relieving pressure on Medisave accounts. Public hospitals provide $80 \%$ of hospital care in Singapore and were all corporatized in the 1990s, meaning that they must function in a business-like manner. In 1999, the government restructured public hospitals into two regional clusters, the National Healthcare Group and Singapore Health Services. Each comprises one of Singapore's two major tertiary hospitals, as well as general hospitals, a number of specialist centres and institutes (such as the National Cancer Centre), and government polyclinics that provide 
primary care services. Private hospitals operate without subsidy. Eighty percent of primary care medicine is privately provided, with only targeted subsidies to provide care for the elderly; government polyclinics serve the remaining $20 \%$ and receive substantial subsidies. Singaporeans are free to choose between providers, but service costs, and the above-mentioned controls on social insurance payments mean most avoid private hospitals. Around $12 \%$ of Singaporeans use traditional Chinese medicine, although this is not eligible for public funding or insurance. Notably, Singapore's public health infrastructure is highly centralized and a health ministry responsibility, with food and hygiene-related disease falling under the Ministry of the Environment. The 2003 SARS outbreak included extensive use of quarantine and fines for non-compliance. The Singapore government tends to place a strong emphasis on fitness and health, evident in workplace-based fitness programmes, and anti-smoking and healthy food campaigns.

\section{The five health systems: commonalities and differences}

\subsection{Regulation}

In each of the five systems, government has a fundamental role as health system regulator, extending across both the public and private components. In South Korea, Taiwan and Japan, where the private sector dominates service provision, government continues to play a key role in setting and monitoring professional and facility standards, as well as regulating fees paid to providers. In all five cases, a central government agency has ultimate responsibility for implementing and monitoring health policy. As a testament to the complexity of health policy, other agencies are also required, such as Hong Kong's Hospital Authority, the insurers in South Korea, Taiwan, Japan and Singapore, and the various disease control agencies.

Although there is stronger private sector presence in the five systems than in most advanced Western countries, there is also considerable government commitment. There are various reasons for this, in addition to the basic need to provide services. In South Korea and Taiwan, social and political pressure led to the initial creation of universal health insurance and these programmes are now viewed as a crucial component of the state. The Japanese government has a core role in negotiating and setting of the fees schedule and, in this respect, 'balancing' the health system [28]. While a minority funder, the Singapore government is deeply engaged in controlling fees, service costs and the shape of the system. In 1990, the Hong Kong government established the Hospital Authority, which has advanced government involvement in health care. In summary, government commitment appears to be increasing over time, in common with OECD membercountries [11], with ever-more sophisticated solutions required for increasingly complex issues.

\subsection{Funding}

The organization of funding varies widely across the five systems. In Hong Kong, the general tax pool remains dominant, particularly for hospital care, while, in the others, insurance is the norm. In none of the five could it be said that funding arrangements or resources are adequate or not debated. The arrangements confirm suggestions elsewhere that there are many options and variations on themes, but no single answer for how best to fund health services $[29,30]$.

In each of the health systems (with the possible exception of Japan) total health expenditure remains low by developed world standards. At the same time, each performs very well. Patients can generally expect a high standard of care across the spectrum of service delivery, and there is virtually universal service access. That said, service co-payments in South Korea, Singapore and possibly Taiwan pose potential access barriers for many, raising questions about the adequacy of their health funding arrangements. Under pressure to extend service coverage, and do so in a precarious economic environment, the era of low-cost highperforming health systems of these 'tiger' economies appears to be under threat. Whether these territories, along with Hong Kong, will accept expenditure levels nearer the OECD average of $8.4 \%$, or whether they will engage in concerted attempts at rationing, remains to be seen.

A notable characteristic of the insurance arrangements in Japan, South Korea and Taiwan is the fact that there is virtually no insurer competition, combined with a single government-managed fee schedule. This contrasts with the situation in the United States of 
multiple competing insurers and fee structures [31,32, pp. 64-78]. The social insurance schemes of South Korea and Taiwan bear both similarities and differences in that the national insurer in Korea is a not-for-profit entity under close and heavy monitoring by the government while Taiwan has a government-run national insurer. Both systems are a single-payer funded by a mix of employer and employee contributions and government supplements, in contrast to the still fragmented state in Japan. However, they are far from trouble free. South Korea faces difficulties with fee structures and insurance coverage, while Taiwan's system contains some perverse incentives, such as promoting the growth of large and expensive hospitals, and could require reform.

Budgetary pressure is common to all five systems, with differing responses. In Hong Kong, there is government support for establishing Singapore-style insurance. However, this idea has not been well received with political reluctance to move away from the status quo. A government advisory committee is expected to submit recommendations on health care financing reform in 2006 [25]. Singapore continues to add new insurance and subsidy schemes to cover emerging and newly recognized at risk groups such as the elderly; it has also raised account thresholds and premium rates, as has Taiwan. In South Korea, there is growing pressure to raise premiums or develop new funding sources to reduce patient co-payments. Japan, meanwhile, faces pressures related to economic stagnation and to funding long-term aged care. Its response has been to raise insurance premiums, adjust regulations and create new long-term aged care insurance. Across the five systems, formal rationing techniques, such as patient and funding prioritization methods found in many developed countries today [33-35], are almost non-existent.

One of the more interesting features of the five systems is the way public funding is used in different parts of the health sector for different purposes and with different ramifications. In Hong Kong, public funding is largely consumed by hospitals, with very little going to primary care. Thus, many patients patronize hospitals due to lower fees, increasing public sector pressure. In Japan, South Korea and Taiwan, public funding is used largely to support social insurance. The Singapore government uses funding (and hospital ownership) in a calculated manner to control service costs and subsi- dize care, in turn limiting expenditure from insurance accounts and providing incentives for private providers to keep costs down.

\subsection{Provision}

Variations in provision are also evident across the five systems. A common theme is private sector dominance in primary medical care. However, in all cases, government is also involved in some form, providing basic low-cost services. Thus, another common theme is a 'safety net' of some sort to ensure health care provision for the less well-off. This is also expressed elsewhere in the systems. Hong Kong's policy is not to deny services to those in need. South Korea's social health insurance covers the entire population, but government-funded Medicaid pays insurance premiums for the poor and more generous insurance benefits. Both Japan and Taiwan's insurance cover the entire population. Singapore's Medifund assists those in dire need.

There are elements of organized primary care group practices in Hong Kong and Singapore and, to a lesser degree, in Japan, South Korea and Taiwan. Traditional Oriental medicine is widely practised and utilized in all five systems. In most cases, its delivery is completely separate from mainstream Western medicine. South Korea, Japan and Taiwan each allow for social insurance to pay for some traditional practices. Hong Kong is the only system that formally recognizes traditional medicine with its Traditional Chinese Medicine Council.

At the secondary and tertiary levels, there are notable differences in organization. Government dominates hospital services in Hong Kong and Singapore. In Hong Kong, the advancing quality and attractiveness of public hospitals is the source of creeping public expenditure and a concern for private providers. South Korea, Japan and Taiwan can be grouped together as systems where hospital services are almost entirely provided in the private sector.

There are few examples across the five territories of integration between different service providers and levels of care. Singapore has made some attempt at integration with its two regional health clusters although, required to 'compete' with one another [7], these clusters have similarities to North America's managed-care organizations. The Hong Kong government has issued 
various policy statements in recent years outlining its desire for integration. However, practical initiatives are yet to surface. Integration does not presently feature in the policy dialogue or systems of South Korea, Japan or Taiwan and is probably a function of the predominant private provision of services and the fact that most clinics and hospitals operate independently.

Although a recognized issue, there are only limited quality improvement initiatives in each of the five systems where the tendency is toward developing methods of accreditation and routine reporting of medical errors. This reflects a variety of factors: that policymakers, service providers and the public have yet to fully embrace the concept; that the dominant private sector and medical profession is resistant to quality control regulations; a lack of routinely collected quality data; and an assumption that market competition promotes service quality.

Finally, in each of the five systems the state has a key role in protecting and promoting public health. Singapore possibly represents the strongest and most coherent commitment to public health which is evident beyond the health sector in the government's general philosophy of promoting healthy living. In Japan, the screening programme, run through a national network of public health centres, features prominently. In South Korea, a range of basic public health services and programmes exist, but these have not been a core component of health policy. However, the emphasis is shifting with the recent increase in health promotion funds resulting from tobacco tax. Taiwan has a long history of public health administration and a comprehensive network of district offices coordinated by the central Department of Health. However, in a system driven by social insurance, public health takes a back seat. In Hong Kong, a separate Department of Health has public health responsibilities. The inadequacy of public health structures and their lack of communication with the private sector has been highlighted in recent years, particularly during the SARS outbreak. In response, a new Centre for Health Protection was created.

\section{Conclusion}

This article described and compared elements of the regulation, funding and provision of health care in five advanced Asian territories. The material in the article points to various questions and conclusions.

First, while all five systems face similar problems, including how to curtail costs, stem demand, protect and promote public health, and provide accessible, efficient and high quality services, each has a unique set of responses and structure. This confounds development of classifications that might assist understanding of health systems in advanced Asia. For instance, even between South Korea and Taiwan, which share a legacy from Japan, and have similar funding and provision systems, the proportion of public expenditure (and therefore state involvement) differs considerably. One area that could be conducive to categorization is primary medical care, with private sole practitioners dominant in each system, alongside significant Oriental medicine presence. Again, however, there are variations, in particular with funding, and private practitioners dominate primary care in many Western countries so this trait is not unique to the advanced Asian systems. A characteristic possibly not as starkly demonstrated elsewhere in the developed world is the almost total lack of integration and, in Japan, South Korea and Taiwan, differentiation, between primary and hospital care found in the five systems.

At a broader public policy and conceptual level, commitment in South Korea, Taiwan, and Singapore to high levels of private provision has been suggested to support the notion of 'productivist welfare capitalism', where '. . . social policy aims chiefly to boost economic development' [36, p. 165]. However, as argued elsewhere, the 'productivist' approach appears to be under threat [37]. As noted in this article, each of these three societies seems to be inevitably moving toward greater state involvement in health care regulation, funding and provision, and health has become an autonomous and critical policy field. Driving this are issues largely independent of the economy, including population ageing, the emergence of new infectious diseases, and international debates over the right to good health care, and obligation to provide robust and accessible health services [38]. Thus, the explanatory value of "productivism' may be decreasing, at least with regard to health. Nonetheless, the common concerns driving the changing role of the state in advanced Asia's health systems provide a strong reason to continue studying them.

Second, none of the five systems is ideal nor straightforward. Each features positive and negative elements. 
For example, for the most part, Singapore's low-cost funding and delivery structures serve the population well. However, access to high-tech expensive procedures is limited. Hong Kong's advanced public hospitals are among the world's best, yet the system lacks effective means to control access and costs and there is no system integration; integration is also lacking in Japan, South Korea and Taiwan. The insurance schemes in South Korea and Taiwan both face considerable financial pressure. Japan, too, faces pressures of an expanding health budget and ageing population. The imperfections in the various systems suggest that policymakers should be cautious when seeking to emulate 'successful' policies of other health systems, as noted elsewhere [39]. It will be interesting, for instance, to see whether the move in the United States to establish medical savings accounts is positive over the longer-term, or whether the complexity Singapore increasingly faces casts doubts [40]. Clearly, the policy transfer that has taken place across the five systems also has implications. If social insurance, in particular, and a strong private sector underpin systems that may eventually face serious reform pressures, then they may have been better served by seeking lessons from elsewhere.

At a wider system level, each is a result of its unique heritage so that none of the systems is replicable. Thus, a key lesson may be that policymakers should not necessarily look to emulate the health systems of advanced Asia, but instead study how each has dealt with generic issues such as cost-containment, equity and quality.

Third, following the above, each of the systems, with possible exception of Singapore, appears to be in need of reform. Japan, Hong Kong, South Korea and Taiwan all have well-identified structural problems, including governance issues (in Hong Kong), sustainability of funding and funding machinery, and adequacy of service provision landscapes, particularly with regard to patient access and service integration among the many public and private providers. The combination of insurance and a predominant private sector could pose problems for integration, as incentives may need to be built into payments if provider collaboration and information sharing are to be embraced. There is also, in each of the systems, with possible exclusion of Singapore, widespread scope for new cost containment measures such as those used elsewhere [33]. While encouraging for patients and providers, the open-access approaches of Hong Kong, Japan, South Korea and Taiwan are clearly a serious concern for the respective governments. That said, South Korea and Singapore face difficulties in reducing access barriers.

Questions abound over whether such problems can be managed and how, and whether the five systems face crisis. For example, with the exception of Japan, each serves a relatively young population and has only more recently engaged in health service expansion, which may be the most important explanation for their comparatively low GDP health expenditures. Population ageing will exacerbate the pressures outlined above. Clearly, there are various options available including: some combination of increased health care taxes, social insurance and state funding; improving primary care and reducing access barriers; integrating, rationing and carefully managing services; and developing specific funding mechanisms that target aged care as in Japan and Singapore. As noted above, it may take particularly strong political leadership and will either to improve existing institutional arrangements or reform them. However, as the South Korean experience illustrates, compromise is often central to reform efforts, meaning that financial sustainability of the systems will continue to be a major policy issue.

\section{Acknowledgements}

The authors are grateful to the two anonymous referees for comments on a prior draft. Any errors and omissions remain the authors' responsibility.

\section{References}

[1] Marshall K, Butzback O, editors. New social policy agendas for Europe and Asia: challenges, experience, and lessons. Washington, DC: The World Bank; 2003.

[2] Ramesh M. Welfare capitalism in Southeast Asia: social security, health and education policies. Houndmills: Macmillan; 2000.

[3] Ramesh M. Social policy in East and Southeast Asia: education, health, housing and income maintenance. London: RoutledgeCurzon; 2004.

[4] Tang K-L. Social welfare development in East Asia. Houndmills: Macmillan; 2000.

[5] Holliday I, Wilding P, editors. Welfare capitalism in East Asia: social policy in the tiger economies. Houndmills: Palgrave Macmillan; 2003. 
[6] Holliday I. East Asian social policy in the wake of the financial crisis: farewell to productivism? Policy and Politics 2005;33(1):145-62.

[7] Holliday I. In: Holliday I, Wilding P, editors. Health care welfare capitalism in East Asia: social policy in the tiger economies. Houndmills: Palgrave Macmillan; 2003. p. 70-98.

[8] Ramesh M. Health policy in the Asian NIEs. Social Policy and Administration 2003;37(4):361-75.

[9] Ramesh M, Holliday I. The health care miracle in East and Southeast Asia: activist state provision in Hong Kong, Malaysia and Singapore. Journal of Social Policy 2001;30(4): 637-51.

[10] Docteur E, Oxley H. Health care: a quest for better value. OECD Observer 2003;238(July):18-23.

[11] OECD. OECD health data. Paris: Organisation of Economic Cooperation and Development; 2003.

[12] OECD. OECD health data. Paris: Organisation for Economic Cooperation and Development; 2005.

[13] World Health Organization. The World Health Report 2003. shaping the future. Geneva: World Health Organization; 2003.

[14] HKSAR Government. Hong Kong 2003. Hong Kong: Information Services Department; 2003.

[15] Singapore Ministry of Health, Ministry of Health Website, Singapore, 2004. http://www.moh.gov.sg/.

[16] Central Intelligence Agency, The World Factbook 2003, Washington, DC, 2003. http://www.cia.gov/cia/publications/ factbook/index.html.

[17] World Health Organization. Tobacco control country profiles. Geneva: World Health Organization; 2003.

[18] Taiwan Department of Health, Department of Health, Taipei, Taiwan, ROC, 2004. http://www.doh.gov.tw/english/.

[19] Mossialos E, Dixon A. Funding health care: an introduction. In: Mossialos E, Dixon A, Figueras J, Kutzin J, editors. Funding health care: options for Europe. Buckingham: Open University Press; 2002.

[20] Kwon S, Pharmaceutical Reform. Physician strikes in Korea: separation of drug prescribing and dispensing. Social Science \& Medicine 2003;57(3):528-38.

[21] Republic of China Bureau of National Health Insurance, NHI Summary Statistics, 2004. Available at http://www.nhi.gov.tw/ $01 \mathrm{intro} / \mathrm{statistic/s} 20 . \mathrm{htm}$.

[22] Chiang TL. Analysis on trends for health care expenditures in Taiwan. Taiwan Journal of Public Health 2003;21:157-63 (in Chinese).

[23] Cheng CM. Taiwan's New National Health Insurance Programme: genesis and experience so far. Health Affairs 2003;22(3):61-76
[24] Health and Welfare Bureau. Lifelong investment in health: consultation document on health care reform. Hong Kong: Health and Welfare Bureau; 2000.

[25] Health and Medical Development Advisory Committee. Building a healthy tomorrow. Hong Kong: Government Logistics Department; 2005.

[26] Gauld R, Gould D. The Hong Kong Health Sector: development and change. Dunedin/Hong Kong: University of Otago Press/Chinese University Press; 2002.

[27] SARS Expert Committee. SARS in Hong Kong: from experience to action. Hong Kong: SARS Expert Committee; 2003.

[28] Campbell JC, Ikegami N. The art of balance in health policy: maintaining Japan's low-cost, Egalitarian system. Cambridge: Cambridge University Press; 1998.

[29] Mossialos E, Dixon A, Figueras J, Kutzin J, editors. Funding health care: options for Europe. Buckingham: Open University Press; 2002.

[30] Hussey P, Anderson GF. A comparison of single- and multipayer health insurance systems and options for reform. Health Policy 2003;66(3):215-28.

[31] Kovner A, Jonas S, editors. Health care delivery in the United States. 7th ed. New York: Springer Publishing Company; 2002.

[32] Scott C. Public and private roles in health care systems: reform experiences in seven OECD countries. Buckingham: Open University Press; 2001.

[33] Coulter A, Ham C, editors. The global challenge of health care rationing. Buckingham: Open University Press; 2000.

[34] Hughes D, Light D, editors. Rationing: constructed realities and professional practices. Oxford: Blackwell; 2002.

[35] Ham C, Robert G, editors. Reasonable rationing: international experience of priority setting in health care. Buckingham: Open University Press; 2003.

[36] Holliday I, Wilding P. Conclusion. In: Holliday I, Wilding P, editors. Welfare capitalism in East Asia: social policy in the tiger economies. Houndmills: Palgrave Macmillan; 2003. p. 161-82.

[37] Ramesh M. Globalisation and social security expansion in East Asia. In: Weiss L, editor. States in the global economy: bringing domestic institutions back in. Cambridge: Cambridge University Press; 2003.

[38] Roberts M, Hsiao W, Berman P, Reich R. Getting health reform right: a guide to improving performance and equity. New York: Oxford University Press; 2004.

[39] Rose R. Lesson drawing in public policy. New Jersey: Chatham House; 1993.

[40] Robinson JC. Health savings accounts: the ownership society in health care. New England Journal of Medicine 2005;353(12): 1199-202. 